\title{
Questões éticas referentes às preferências do paciente em cuidados paliativos
}

Carolina Becker Bueno de Abreu ${ }^{1}$, Paulo Antonio de Carvalho Fortes ${ }^{2}$

\section{Resumo}

O respeito à autonomia do paciente é um princípio ético reconhecido em diversas áreas da assistência à saúde, incluindo os cuidados paliativos, porém nem sempre as preferências do paciente são respeitadas. Uma melhor compreensão das questões éticas relacionadas ao exercício da autonomia do paciente em cuidados paliativos é importante passo para embasar juízos éticos ponderados no cotidiano da assistência. Tendo isso em vista, este trabalho objetivou identificar e analisar questões éticas relacionadas às preferências do paciente e reconhecidas por profissionais no cotidiano de uma equipe de cuidados paliativos à luz do referencial bioético da casuística. Foram entrevistados onze profissionais de nível superior. As principais questões éticas identificadas foram: respeito à autonomia do paciente; veracidade e direito à informação; habilidades de comunicação; cerco do silêncio; participação no processo de deliberação; escolha do local de tratamento e morte.

Palavras-chave: Cuidados paliativos. Autonomia pessoal. Preferência do paciente.

\section{Resumen}

\section{Las cuestiones éticas relacionadas con las preferencias del paciente en los cuidados paliativos}

El respeto a la autonomía del paciente es un principio ético reconocido en muchas áreas de la salud, incluyendo los Cuidados Paliativos, pero no siempre se respetan las preferencias del paciente. Una mejor comprensión de las cuestiones éticas relacionadas con el ejercicio de la autonomía del paciente en los Cuidados Paliativos es un paso importante para apoyar los juicios éticos ponderados en la práctica diaria de la asistencia. Teniendo esto en cuenta, este estudio tuvo como objetivo identificar y analizar las cuestiones éticas relacionadas con las preferencias del paciente y reconocidas por los profesionales en el día a día de un equipo de cuidados paliativos en el marco bioético de la casuística. Se entrevistó a once profesionales de nivel superior. Se identificaron las principales cuestiones éticas: el respeto a la autonomía del paciente, veracidad y el derecho a la información, habilidades de comunicación, asedio del silencio, participación en el proceso de deliberación, elección del lugar de tratamiento y muerte.

Palabras-clave: Cuidados paliativos. Autonomía personal. Prioridad del paciente.

\begin{abstract}
Ethical issues related to patient preferences in palliative care

The respect for patient's autonomy is an ethical principle recognized in many areas of health care including palliative care, but not always the patient's preferences are respected. A better understanding of ethical issues related to the exercise of patient's autonomy in Palliative Care is an important step to support ethical judgments in daily practice. Therefore, this study aimed to identify and analyze ethical issues related to patient preferences recognized by professionals in the daily life of a Palliative Care team under the framework of Casuistry. Eleven practitioners were interviewed. The main ethical issues identified are: respect for patient autonomy, veracity and right to information, communication skills, conspiracy of silence, participation in the deliberation process, choice of place of treatment and death.

Key words: Palliative care. Personal autonomy. Patient preference.
\end{abstract}

Aprovação Coep 181/11

1. Doutora caro@becker.eng.br - Faculdade de Saúde Pública da Universidade de São Paulo/Faculdade de Ceilândia, Universidade de Brasília, Ceilândia/DF, Brasil 2. Doutor pacfusp@usp.br - Faculdade de Saúde Pública da Universidade de São Paulo, São Paulo/SP, Brasil.

\section{Correspondência}

Carolina Becker Bueno de Abreu - Faculdade de Ceilândia, Universidade de Brasília (UnB). Centro Metropolitano, Conjunto A, Lote 1 CEP 72220-900. Ceilândia/DF, Brasil.

Declaram não haver conflito de interesse. 
Jonsen, Siegler e Winslade ${ }^{1}$ entendem preferências do paciente no contexto da ética clínica como sendo as escolhas que a pessoa faz quando se depara com decisões sobre sua saúde e tratamentos, a partir de suas experiências, crenças e valores. Constituem assim o núcleo ético e legal da relação clínica, a partir do qual o paciente deve ser respeitado em suas decisões após analisar a recomendação médica.

O princípio moral subjacente é o da autonomia. Na relação terapêutica devem ser respeitadas a autonomia do profissional e do paciente. O profissional deve ter respeitado o seu melhor julgamento e a objeção de consciência. O paciente, por sua vez, deve ser estimulado a manifestar suas preferências ou propor alternativas às propostas feitas pelo profissional.

$O$ respeito à autonomia do paciente tem significância clínica, legal e psicológica. Do ponto de vista clínico, favorece confiança na relação terapêutica, maior cooperação do paciente e satisfação com relação ao tratamento. Em termos legais, respalda os direitos individuais sobre o próprio corpo. Do ponto de vista psicológico, oferece ao paciente senso de controle sobre a própria vida e de valor pessoal ${ }^{1}$.

Sendo princípio ético reconhecido em diversas áreas da assistência à saúde, o respeito à autonomia do paciente inclui os cuidados paliativos. Interessante observar, inclusive, que as mudanças na relação médico-paciente, que passou de forte paternalismo ao respeito pela autonomia do paciente, foi um dos fatores que levaram a mudanças no enfrentamento da proximidade da morte na atualidade, reforçando a necessidade de se reconhecer a finitude da vida humana, evitar sua conservação de forma incondicional, aplicar todas as medidas necessárias e disponíveis para melhorar sua qualidade, e não sua quantidade, manter o paciente (e seu representante) devidamente informado e respeitar seu critério para que possa participar da deliberação e decidir, dentro da legalidade vigente, sobre o tratamento e alguns aspectos relacionados às circunstâncias de sua morte ${ }^{2}$.

Em paralelo, Tapiero ${ }^{2}$ ressalta que apesar da crescente tendência de se respeitar a autonomia do paciente, na prática não é habitual que decida sobre as circunstâncias de sua morte, mesmo porque é frequente se lhe ocultar a condição de moribundo e, por isso, não é comum que a forma de morrer dependa de seus critérios, valores e crenças. Bélanger, Rodríguez e Groleau ${ }^{3}$ também concluem que a maioria dos pacientes em cuidados paliativos deseja exercer autonomia, preferindo participar na tomada de decisão sobre o tratamento em algum grau, enquanto só a minoria prefere delegar esse papel.
Estes autores constatam, entretanto, que na prática os pacientes são pouco encorajados a participar da deliberação, as opções são pouco discutidas e o consentimento fica apenas implícito, devido a barreiras relativas à forma como as opções são apresentadas, à tentativa de manter expectativas irrealistas por parte do paciente e família e, ainda, à tendência de adiamento da deliberação. Conclui-se, então, que há diversos obstáculos para que o exercício da autonomia e as preferências do paciente sejam de fato respeitados.

Em geral, as dificuldades podem estar na formação do profissional, na capacidade de comunicação, compreensão e discussão entre os sujeitos envolvidos na relação terapêutica para a tomada de decisão e nos mecanismos que possibilitem sua concretização. Nos cuidados paliativos, o fato de lidar com pessoas com diagnósticos de doenças ameaçadoras à vida, de curso progressivo e incapacitante, torna frequentes os problemas acima listados.

Uma melhor compreensão das questões éticas relacionadas ao exercício da autonomia do paciente em cuidados paliativos é, assim, importante passo para o aprofundamento da reflexão necessária para embasar juízos éticos ponderados no cotidiano da assistência.

\section{Objetivos}

Identificar e analisar questões éticas relacionadas à autonomia do paciente e reconhecidas por profissionais no cotidiano de uma equipe de cuidados paliativos, sob o referencial bioético da casuística.

\section{Procedimentos metodológicos}

Trata-se de pesquisa exploratória, de abordagem qualitativa, em que todos os profissionais de nível superior atuantes há pelo menos um ano na equipe de cuidados paliativos de um hospital geral da cidade de São Paulo/SP, exceto a coordenadora da equipe, foram convidados a participar.

As entrevistas foram aplicadas em agosto de 2011, durante o expediente dos trabalhadores, com duração média de 30 minutos. À exceção de uma entrevista por telefone, as demais foram aplicadas no local de trabalho dos sujeitos. Foi mantido o anonimato dos sujeitos que aceitaram participar da pesquisa, sendo apresentados sob forma numérica. 
Foram aplicadas entrevistas semiestruturadas, cujo roteiro foi elaborado pelos pesquisadores e validados por meio de pré-teste. A análise temática adotou a casuística como referencial teórico. As questões norteadoras foram: "Por favor, comente sobre como é o trabalho desenvolvido pela equipe de cuidados paliativos e quais as principais dificuldades enfrentadas"; "Com quais problemas éticos o(a) senhor(a) se depara ao atuar nesse serviço?"; "O que facilita a discussão e tomada de decisão nessas situações?"; "Que tipo de apoio seria interessante para ajudar a lidar com esses problemas éticos?"

A pesquisa foi aprovada pelo Comitê de Ética em Pesquisa da Faculdade de Saúde Pública da Universidade de São Paulo (Ofício 181/11) e os entrevistados foram esclarecidos acerca do caráter da pesquisa, objetivos, procedimentos e possibilidade de recusa a qualquer momento, manifestando o consentimento mediante assinatura de termo de consentimento livre e esclarecido (TCLE).

\section{Resultados e discussão}

Foram entrevistados onze profissionais: três enfermeiros, cinco médicos, um nutricionista, um fisioterapeuta e um assistente social. A média de idade dos entrevistados é 41,3 anos, variando de 28 a 51. A média de tempo de exercício profissional geral foi de 14,5 anos, variando de 5 a 25 anos. Os entrevistados trabalham na área de cuidados paliativos há 5,6 anos em média, variando de um ano e meio a 12 anos. Com relação à crença religiosa, três se declararam católicos, três protestantes de diversas confissões, um espírita e um judeu, e três afirmaram não ter religião definida. Alguns participantes já tinham experiência em cuidados paliativos previamente ao ingresso na equipe estudada. A média de tempo dedicada especificamente ao trabalho na equipe estudada é de 3,77 anos, variando de 1 a 4 anos.

Ao longo das entrevistas foram observadas as seguintes questões éticas relacionadas às preferências do paciente: respeito à autonomia do paciente; veracidade e direito à informação; comunicação e respeito no recebimento de más notícias; cerco do silêncio; participação na deliberação e tomada de decisão: paciente, equipe e família; preferências quanto ao local de tratamento e morte.

\section{Respeito à autonomia do paciente}

Quando o paciente tem condições de julgamento, a equipe esclarece a situação e leva em conta sua opinião. Quando há recusa de alguma intervenção, a documentação em prontuário se faz necessária para respaldar a equipe: "Se o paciente tem possibilidade de julgamento a gente chega muito no paciente e pergunta, conversa, esclarece. $O$ que o paciente não quer, a gente procura deixar tudo muito bem documentado em prontuário pra que isso não venha trazer problemas" (E4).

A existência de limite ao respeito à autonomia do paciente que recusa uma intervenção sobre a qual o profissional tem segurança de que seria proveitosa é, por sua vez, questionada: "Quando eu chego pra um paciente que precisa fazer exercício, um paciente que se beneficiaria muito de um exercício, enfim... E ele me diz que ele não quer fazer (...). Quando, até onde respeitar a vontade do paciente se eu profissional sei que aquilo faria diferença pra ele? Até onde respeitar? Até quando deixá-lo exercer a sua autonomia?" (E2).

No discurso a seguir verificamos que, ao longo do tempo em que atua nos cuidados paliativos, E2 tem amadurecido com relação ao respeito à autonomia do paciente: " $E$ eu fui entendendo que nem sempre a minha vontade era soberana aqui". A entrevistada reconhece que a formação profissional direciona e cria expectativas com relação à proatividade do profissional em promover mudanças substanciais a partir dos recursos terapêuticos de que dispõe.

Entretanto, a experiência que adquiriu atuando em cuidados paliativos agregou a consciência de que, por vezes, a atuação é restrita ao que ela chama "vigilância", e se refere à atenção dada aos pacientes que não desejam a atuação específica que tem a oferecer: "A minha formação é essa: eu tenho que promover alguma mudança. Então eu demorei, até hoje isso pra mim é uma coisa que me incomoda quando eu acho que... Somente... Somente vigiar..." (E2).

Neste exemplo podemos notar um conflito entre os princípios de beneficência e respeito à autonomia. Essa postura pode ser paternalista caso contrarie as preferências do paciente e seja justificada pelo objetivo de beneficiar o paciente ou evitar que sofra danos ${ }^{4}$. As circunstâncias concretas de cada caso devem ser analisadas a fim de verificar se é uma atitude paternalista justificável.

Há situações em que, ao contrário da acima relatada, o paciente opta por intervenções agressivas apesar da avaliação do profissional de que isso seria fútil ou lhe traria mais desconforto que benefício ${ }^{5}$. De acordo com Macauley ${ }^{5}$, muitas vezes o consenso é atingido depois de necessário esclarecimento, porém há casos em que a decisão do paciente é mais 
emocional que racional e desistir de intervenções com foco curativo desafiaria o senso de esperança, impondo intensa percepção de fracasso, fraqueza ou covardia ${ }^{5}$.

$\mathrm{O}$ autor argumenta que paliativistas consideram a complexidade do sofrimento humano, expressa inclusive no conceito de "dor total" proposto por Cicely Saunders, mas paradoxalmente resistem a aceitar a possibilidade de o sofrimento emocional de um paciente que aceitou o tratamento paliativo ser mais severo que o sofrimento físico esperado como consequência de um tratamento agressivo. Conclui, então, que cuidados paliativos também têm suas bases valorativas, o que por vezes gera conflitos por propor-se, ao mesmo tempo, uma abordagem centrada no cliente e que prioriza o respeito à autonomia ${ }^{5}$.

Podemos notar, ainda, a valorização da opinião dos familiares nas decisões sobre o paciente e o consequente compromisso de compartilhar com a família todas as informações necessárias: "Porque em cuidado paliativo normalmente a gente não esconde, principalmente do familiar" (E1).

Essa realidade reflete o fato de ser frequente o paciente em cuidados paliativos não estar em condições de deliberar e decidir e, portanto, de exercer autonomia, passando a ser crucial, então, a participação da família a fim de representar os seus valores e interesses, ou o recurso às diretivas antecipadas de vontade, sempre que o paciente as tenha manifestado.

De acordo com Kovács, parte importante dos cuidados no final da vida é facilitar o exercício da autonomia e decisões de pessoas enfermas, que trazem consigo sua biografia ${ }^{6}$.

\section{Veracidade e direito à informação}

$A$ ideia de que a veracidade entre paciente $e$ profissional de saúde (incluindo, muitas vezes, também os familiares do paciente) é fundamental para o exercício da autonomia e para a construção ou manutenção de uma relação permeada de confiança foi explicitada:

"Só a verdade. Entre o médico, equipe, família e paciente. Tenho uns chavões: 'a gente só pode brigar com inimigos que conhece'. Não posso esperar que a família ajude numa decisão - não pode compreender - se eu disser meias verdades. Então dividir $100 \%$ com a família, porque se a família não se sentir segura e acolhida não vai funcionar" (E6).
O direito à informação é amplamente reconhecido pela equipe que estudamos: "Se o paciente tem desejo de saber, como tem um caso aqui, que a paciente ela é totalmente esclarecida e ela induziu a equipe a contar tudo pra ela do que ela tinha e o porquê dos sintomas. Então o próprio paciente muitas vezes induz a equipe a isso e deseja, e também é um direito que o paciente tem" (E1).

As informações acerca do estado clínico são necessárias, ainda, para o paciente poder planejar sobre sua vida e tomar providências frente à proximidade do seu fim: "Eu acho que ele tem o direito de saber aquilo que ele tem e de se planejar em cima do tempo que ele ainda tem pra fazer as suas coisas. Então se ele achar que tá tudo bem, ele pode até morrer achando que tá tudo bem" (E2).

A comunicação foi reconhecida, inclusive, como instrumento fundamental para resolver problemas éticos entre profissionais e paciente/família: "A boa comunicação. Acho que é o principal instrumento entre equipe e estender isso para os familiares do paciente" (E6). Mediante comunicação, respeito à diversidade de opiniões e unidade os consensos devem ser alcançados, iniciando-se entre os próprios membros da equipe:

"Eu acho que é justamente a questão de todos falarem a mesma língua, sabe, de você ter a cabeça aberta e você ter o discernimento pra poder discutilas. Inclusive discuti-las não só na equipe, mas perante a família, né? Perante todo o restante da equipe multidisciplinar. (...) Cada um respeita a sua opinião, mas eu acho que no fundo todos conseguimos chegar num ponto comum. Eu acho que isso minimiza muito a questão dos impasses médicos, a questão de bater de frente em relação a condutas mesmo da equipe em si" (E4).

\section{Comunicação e respeito no recebimento de más noticias}

A compreensão de uma informação depende do sucesso do processo de comunicação. No caso da comunicação entre profissional de saúde e paciente e/ou família, muitas dificuldades de comunicação podem impor-se.

Os pacientes podem ter sua capacidade de compreensão ameaçada ou diminuída em decorrência de estados de humor como ansiedade e depressão, rebaixamento de nível de consciência, comprometimento cognitivo, sensorial ou pela própria dor e outros sintomas intensos. A participação da família ou representante legal do paciente em 
relação às decisões sobre a condução do caso passa a ser maior.

Além disso, profissionais de saúde podem ter dificuldades para empreender uma eficaz interação com o paciente/família por falta de habilidade em comunicar-se de forma simples, acessível e de acordo com as características dos interlocutores, ou pelo receio de sobrecarregar emocionalmente o paciente com uma má notícia ou mitigar sua esperança.

Vale considerar que assim como o acesso à informação é identificado como elemento ético importante na relação terapêutica, a qualidade da comunicação também traz implicações éticas, vez que deve beneficiar o paciente e evitar os danos emocionais que uma má notícia pode trazer.

Muitos profissionais, e por vezes familiares, se questionam sobre se o paciente deseja realmente saber a verdade, se isso pode lhe prejudicar, se seria melhor omitir a verdade ou não ser veraz para preservar a esperança. Essa preocupação foi apresentada: "Até onde a gente vai? (...) Então é lícito a gente expô-la diante de uma verdade que às vezes ela não quer ver?" (E9). Esta colocação remete a uma exceção à regra de consentimento informado reconhecida no âmbito da assistência à saúde. Trata-se do chamado privilégio terapêutico, caracterizado pela omissão de informações sobre o estado de saúde do paciente baseado num julgamento fundamentado do médico de que divulgar a informação seria potencialmente prejudicial a um paciente que está deprimido, emocionalmente esgotado ou instável ${ }^{4}$.

Compreende-se assim que as informações devem ser oferecidas ao paciente com cuidado, respeitando também o direito de "não saber". Foi reconhecida uma diferença cultural entre o Brasil e países de cultura anglo-saxônica, que permite que, no Brasil, a informação seja dada de forma mais cautelosa: "A gente tem a sorte ética... uma sorte humana de não estar em uma cultura anglo-saxônica, dentro de uma cultura ainda não tão litigiosa, que eu precise dizer pro paciente: tempo de vida; perspectivas; chances etc. A gente tem a possibilidade latina de contar o que ele aguenta ouvir, na velocidade que ele aguenta ouvir, oferecer silêncio... e esperar" (E7).

Nesse sentido, Pessini ${ }^{7}$ concorda que $a$ atitude anglo-saxã em relação à comunicação de diagnóstico/prognóstico vai mais na direção da verdade objetiva dos fatos, o que contrasta com a nossa cultura latina, que faz uma leitura emocional da verdade médica com a preocupação de proteger o paciente da verdade. Reconhece-se também que ter acesso à informação não priva o paciente do sofrimento, mas a comunicação respeitosa lhe traz benefícios:

"Quando o paciente sabe, a gente toca isso na lin-

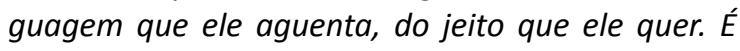
muito legal. Geralmente quem viveu muito bem, vai morrer muito bem. Quem consegue ter transparência nessa hora, não quer dizer que não sofre, que não angustia" (E7).

Enquanto a mentira e a omissão isolam o paciente, a oportunidade de partilhar os medos, angústias e preocupações pode trazer benefício terapêutico, sempre que se tenha cuidado com relação ao que, como, quando, quanto e a quem se deve informar ${ }^{7}$. Assim, foi feita referência à forma na qual as informações devem ser oferecidas ao paciente: "Lógico que a verdade não precisa ser "entuxada", mas com delicadeza..." (E6).

Fallowfield e colaboradores ${ }^{8}$ ressaltam ser frequente profissionais de saúde alegarem que a maioria dos pacientes não deseja saber a verdade, pois perderiam a esperança, ficariam oprimidos e deprimidos, se tornando assim incapazes de aproveitar o tempo que Ihes resta. Entretanto, há pouca evidência desse processo. Ao contrário, a omissão de informações importantes sobre a realidade do estado de saúde do paciente não o protege do sofrimento psicológico. O resultado mais frequente dessa atitude evasiva do profissional é, para o paciente, maior angústia, dificuldade e lentidão no processo de ajustamento necessário.

Oliveira e colaboradores ${ }^{9}$ observaram que $90 \%$ dos médicos entrevistados afirmaram prover suporte emocional ao paciente, porém $20 \%$ informaram não conversar sobre a doença nem comunicar o diagnóstico verdadeiro ao paciente em fase terminal. Além disso, apesar de $70 \%$ dos médicos concordarem que a discussão aberta sobre questões de vida e morte não causa danos ao paciente, $80 \%$ deles preferem não esclarecer a estimativa de tempo de vida para os pacientes.

A comunicação dos médicos participantes do estudo acima citado com os familiares dos pacientes também é restrita. Oitenta por cento dos entrevistados afirmaram apenas esclarecer dúvidas dos parentes e $30 \%$ relataram não dar apoio nem conversar abertamente com eles acerca da doença do paciente ${ }^{9}$. Em revisão de literatura sobre comunicação entre profissional de saúde e paciente de cuidados paliativos, Slort et al. ${ }^{10}$ constataram que as barreiras mais frequentemente citadas para a comunicação foram: a falta de tempo do profissional; a ambiva- 
lência ou falta de desejo do paciente em saber sobre o prognóstico; e o fato de o profissional não falar honestamente sobre diagnóstico ou prognóstico.

Em contrapartida, os facilitadores à comunicação mais citados foram: a disponibilidade do profissional; relacionamentos duradouros entre paciente e profissional; o profissional manifestar compromisso, abertura e permissão para discutir qualquer assunto, sendo honesto e amigável, ouvindo de forma ativa e levando o paciente a sério; tomar iniciativa em tocar temas relacionados à finitude, sem omitir informações; negociar opções terapêuticas, desejando falar sobre diagnóstico e prognóstico, preparação para a morte, questões psicológicas, sociais e espirituais do paciente e suas preferências.

Foi identificada ambivalência por parte de paciente e profissional acerca da discussão de prognóstico. Muitos pacientes manifestam querer informação completa, mas às vezes são relutantes em saber de um mau prognóstico. Por sua vez, profissionais referem ser conscientes do impacto das informações sobre a esperança do paciente e acham difícil julgar o momento adequado para começar a discussão sobre essas questões ${ }^{10}$.

Comparando sua pesquisa com a literatura sobre comunicação entre profissional e paciente em contextos gerais, Slort et al. ${ }^{10}$ concluíram que a comunicação em cuidados paliativos não é tão diferente. $\mathrm{O}$ que poderia ser entendido como questões específicas são: a maior dificuldade de predizer 0 curso clínico da doença, que leva a maior incerteza acerca do prognóstico; a ambivalência sobre como lidar com informações referentes a um mau prognóstico; a relevância de reavaliar continuamente as necessidades de pacientes e família no tocante à oferta de informação, vez que as ideias e preferências do paciente podem mudar ao longo do tempo.

Além disso, profissionais devem distinguir entre problemas do paciente e suas necessidades percebidas, pois o paciente pode não querer abordar determinados problemas. Com relação aos temas da comunicação, questões mais específicas dos cuidados paliativos são a explanação sobre a fase final da doença, preferências e emoções relativas ao fim da vida, questões espirituais, futilidade terapêutica, opções de tratamento que prolonguem a vida, decisões relativas ao fim da vida e crenças sobre o que há para além da vida ${ }^{10}$.

Os autores sugerem que os profissionais de cuidados paliativos estejam disponíveis para o paciente, tenham uma abordagem aberta e comprometida, ouçam ativamente, tomem iniciativa para falar sobre questões referentes à finitude, reconheçam suas ambivalências e as do paciente sobre determinados assuntos, reavaliem continuamente as necessidades e preferências do paciente e tenham alto nível de habilidades de comunicação para discutir, adicionalmente, questões emocionais e espirituais com o paciente ${ }^{10}$.

\section{Cerco do silêncio}

A dificuldade de falar sobre 0 processo de doença e a expectativa da brevidade da vida é frequente entre profissionais de saúde e também para os próprios pacientes e seus familiares. É comum observar o designado "cerco", "conspiração" ou "pacto" de silêncio, identificado pelos entrevistados como problema ético: "Do ponto de vista ético, o que me chama muita atenção ainda acho que é o cerco do silêncio" (E7).

O cerco do silêncio é definido como o acordo implícito ou explícito, por parte de familiares, amigos e/ou profissionais, de alterar a informação que se dá ao paciente com a finalidade de ocultar-lhe o diagnóstico e/ou prognóstico e/ou gravidade da situação ${ }^{11}$. E7 afirma que o cerco do silêncio: "É um diagnóstico em cuidado paliativo onde você percebe que esse paciente não está participando ativamente das escolhas sobre si porque não sabe o que tá acontecendo".

Quando quem detém a informação é a família, ela detém o poder de decidir sobre o paciente: "As famílias tomarem conta das decisões, das escolhas, e do diagnóstico que pertence ao paciente" (E7). O intuito de quem impõe o cerco do silêncio é evitar o sofrimento do outro: "Ele não vai aguentar saber"; "Vai sofrer muito" (E7). Porém, de acordo com a entrevistada, além de não excluir o sofrimento o cerco do silêncio priva a pessoa da possibilidade de exercer autonomia: "Na verdade, essas pessoas estão sofrendo... privando o paciente da escolha (...) causa um grande desgaste na família e também na gente, é os pacientes que não sabem o que tá acontecendo" (E7).

Foi descrita cena em que o cerco do silêncio permeia as relações: "Lá na casa, no portão, alguém da família me pede pra não falar sobre o assunto, sobre o diagnóstico, sobre prognóstico, sobre tempo de vida, sobre nada praticamente, né? Na maioria das vezes, a gente sabe que o paciente já sabe $e$ existe a tal conspiração do silêncio" (E10). Ao ressaltar a dialética do cerco do silêncio entre paciente e família, a entrevistada afirma que, muitas vezes, o contrário das situações relatadas também ocorre, 
sendo o paciente quem detém a informação, sem querer que a família saiba:

"O paciente não fala pra família, eu imagino que pra família não sofrer... mais... E a família não fala nada pro paciente, também com o mesmo objetivo. E fica tudo muito... fica uma situação calada e sofrida" (E10).

Além de causar sofrimento à família e ao paciente, o cerco do silêncio impõe um dilema para os profissionais: "Quem que eu vou acatar? E a gente vai tateando e... né? E... deixando a coisa fluir um pouco devagar. E acaba... no final, eu acho que acaba tudo dando certo. Mas é um dilema" (E10); "Essa questão do cerco do silêncio é uma coisa que sempre me angustiou porque eu não sei de que lado eu fico... Então eu prefiro ficar na minha mesmo. Eu prefiro ficar bem quieta" (E2).

Fallowfield, Jenkins e Beveridge ${ }^{8}$ afirmam que embora a motivação por trás do cerco do silêncio seja bem intencionada, resulta em elevado estado de ansiedade, medo e confusão, e não serenidade e segurança. Além disso, nega aos sujeitos a oportunidade de reorganizar e adaptar suas vidas para realizar metas mais plausíveis, pautadas por esperanças e aspirações realistas. No caso dos cuidados paliativos, pacientes necessitam de informações claras para planejar e tomar decisões sobre o local da assistência e da morte, colocar assuntos pendentes em ordem, despedir-se, fazer pazes e protegerse de terapias fúteis. Os autores concluem que a oferta de informações honestas ao paciente é um imperativo ético ${ }^{8}$.

Participação na deliberação e tomada de decisão: paciente, equipe e família

Um entrevistado considerou como importante problema ético a tomada de decisão unilateral por parte da equipe médica sobre questões relativas ao investimento terapêutico: "O que me deixa absolutamente chocada, horrorizada, é a decisão unilateral de uma equipe médica de não mais investir em paciente ou não. E o termo é 'investir', como se o paciente fosse uma bolsa, um mercado de ações, né? Então, em geral, os médicos avisam que não vão mais fazer... Ainda avisam... talvez..." (E7).

$\mathrm{Na}$ fala acima transcrita verificamos o incômodo pelo fato de a equipe médica não permitir que paciente e família participem de decisão tão importante e também com relação a um termo bastante utilizado que é o "investir", que, em sua opinião, é ambíguo e permite uma visão depreciativa e utilitária sobre o paciente.
Jonsen, Siegler e Winslade ${ }^{1}$ aconselham a nunca alegar futilidade para justificar decisões unilaterais, evitando assim conversas difíceis com paciente ou família, e que se evite o uso do termo futilidade com a família, haja vista sua conotação negativa. Sugerem, ao invés disso, direcionar os esforços para oferecer conforto e paliação ao paciente, pois os prejuízos de uma intervenção mais agressiva podem exceder os benefícios possíveis.

A autonomia do paciente (exercida por ele ou por seu representante) foi reconhecida como importante elemento para a definição da conduta, cabendo à equipe legitimar sua participação no processo deliberativo: "Como a ideia das condutas tem muito a ver com o respeito à autonomia do paciente (...) é uma questão de legitimar esse paciente, essa família" (E7).

A questão da participação da família na tomada de decisão é trazida também com outro foco. Entrevistados manifestaram preocupação pela atribuição, a pessoas leigas, da função de decidir sobre questões técnicas sobre as quais não têm competência:

"Eu vejo acontecer na clínica médica, na geriatria, não com a gente é... Passar pro paciente e pra família dilemas que é da equipe decidir. Por exemplo, se o paciente tem a indicação de algum procedimento e aquele procedimento ele é muito específico, você precisa de formação pra discernir sobre aquele procedimento. Muitas vezes aquilo, ele é jogado a responsabilidade para o familiar (...) Não acho que é ético discutir isso com uma pessoa leiga" (E5).

E6 concorda, ao afirmar que: "Tem coisa que é conduta médica. Daí não existe "o que você quer?", porque é conduta médica, não algo que a família pode escolher". Ante tais constatações as entrevistadas remetem à discussão sobre quais questões e de que forma a família deve participar no processo de deliberação em cuidados paliativos:

"Tudo bem (a familia participar de decisões) em questões como analgesia, sonda para não vomitar... ajudar a escolher entre sonolência ou um pouco de dor... Mas operar ou não, ir para UTI ou não, são outra coisa, são decisões de conduta médica" (E6).

Os discursos expressam, assim, que caberia à equipe discernir sobre quais questões relacionadas ao tratamento do paciente a família pode opinar, e em quais circunstâncias deve ser esclarecida a fim de compreender a conduta decidida pela equipe: "Muitas coisas a família não tem que decidir, mas compreender a sua decisão, porque a conduta é mé- 
dica. O profissional tem que ter isso claro pra ele de até onde a familia pode opinar" (E6). Delegar à família do paciente a responsabilidade por decisões de conduta médica foi identificado como problema, especialmente quando há discordâncias entre membros da família ou entre família e equipe.

As situações citadas pelos entrevistados, em que tais conflitos emergem, vão desde o encaminhamento aos cuidados paliativos, incluindo a indicação de procedimentos menos invasivos e a contraindicação de medidas desproporcionais, ao dilema, de modo especial, entre reanimar ou não o paciente. Nesse sentido, foi referido como problema o fato de muitas vezes a equipe médica que encaminha o paciente ou pede interconsulta não zelar pelo esclarecimento prévio da família:

"A gente esbarra muitas vezes no não falar da equipe médica que está, digamos assim, gerenciando o caso do paciente. $O$ fato de não falar das condições que realmente ele está... A possibilidade de cura que não existe mais, de controle dos sintomas" (E4).

De acordo com um dos entrevistados, a falta de informação da família ocorre mais em função de limitações da própria família do que devido à indisponibilidade da equipe: "Que se houve uma desinformação ou uma não informação, às vezes é muito mais por uma família que não era presente porque o paciente não deixava, ou porque não conseguia ser presente, e que a gente acaba tendo que contar todo o final da história e... Contar qual que é o melhor tratamento para aquele paciente. $E$ induzir essa família a acreditar na gente. A gente tem um problema ético, que é o problema de comunicação" (E7).

Como problema ético, E10 aponta a rejeição da família frente à proximidade da perda do familiar, dificultando entender a ideia de cuidados paliativos, bem como o quanto é inócuo manter alguns procedimentos: "A questão do... principalmente da família, não aceitar cuidados paliativos. É não aceitar que se falem os procedimentos desnecessários... fúteis. $\dot{E}$ muito frequente, também. (...) É muito difícil as pessoas aceitarem que não se faça mais procedimentos, que não se invista em medidas que não vão dar em nada". Pautadas nas mesmas dificuldades as entrevistas também fazem referência a problemas no momento do óbito: "No prontuário estava escrito, mas a gente sabia que havia um litígio entre equipe médica e família. Então, o que fazer?" (E6).
A preocupação dos entrevistados que se pronunciaram a respeito da participação da família na tomada de decisão advém do risco das possíveis implicações jurídicas contra a equipe ou determinado profissional. A próxima fala representa bem essa posição: "Juridicamente, não importa o que a família escolha. A tomada de decisão da família não tem nenhum valor. Aliás, sempre tem um familiar que chega de 'Titirica da Serra' e chega cansando, põe caraminhola na cabeça e vai até o juiz. Se se agarrar ao fato que a familia escolheu, certamente pagará indenização. Mas se for a conduta, é respaldado" (E6).

Tal observação chama atenção à necessidade de integração e coerência entre os membros da equipe e entre eles e a família, para evitar problemas judiciais: "É imprescindível que todos os passos estejam friamente compassados, e também diferenciar o que é conduta médica e no que o familiar pode interferir" (E9). Ressalte-se ainda que: "Acabase chegando a um acordo, mas sempre com muito desgaste, às vezes, com um desgaste muito... muito grande, né. Tem pessoas até agressivas... Até violentas" (E10).

Kovács ${ }^{6}$ relaciona a dificuldade da participação de pessoas leigas nas reflexões e tomada de decisão sobre cuidados no final da vida a atitudes culturais muito arraigadas de negação da morte. A autora sugere debates e esclarecimentos à população como estratégias que possibilitem a preservação da dignidade e qualidade no processo de morrer.

Preferências quanto ao local de tratamento e morte

É comum o paciente internado desejar ser tratado em casa. Nesses casos a equipe deve, então, se empenhar para que esse objetivo se cumpra. 0 fato de o serviço de cuidados paliativos estudado oferecer assistência domiciliar favorece essa possibilidade: "O paciente quer muito ir pra casa. Então a equipe se empenha mais ainda pra tentar mandar essa pessoa pra casa" (E2).

Muitas vezes o paciente deseja falecer em casa, mas isso traz implicações legais importantes: "E essa é uma questão até ética que não é bem acei$t a$, entendeu? E que a gente tem muitas barreiras em caso de óbito no domicílio. Não pelo lado da família, mas pelo lado burocrático mesmo, lá do sistema. Quando uma pessoa morre em casa os trâmites normais quais são? Polícia... IML..." (E1).

Além dos motivos legais apontados, a dificuldade de o paciente falecer em casa mesmo quando 
assim o deseja está, de acordo com os entrevistados, relacionada à incapacidade de a família acompanhar o processo até o final: "Porque a família não tem estrutura pra suportar esse... O falecimento no domicílio" (E10). Os entrevistados também aludem à falta de recursos, por parte da equipe, para que possam dar suporte ao paciente e família nessa situação:

"Uma coisa que seria, que talvez cairia na questão do princípio ético da justiça nos cuidados paliativos é às vezes não ter tantos recursos quanto eu gostaria... pra um paciente que quer estar em casa e a gente não tem um curativo diário, ou a gente não tem uma garantia de transporte imediato, ou a gente não dá conta de uma demanda que poderia ser visita médica semanal, porque a gente tem limite de equipe mesmo" (E7).

Em decorrência, um problema ético muito frequente é o não cumprimento do combinado entre paciente, equipe e família com relação ao local e contexto da morte, quando falecer em casa é desejo manifesto do paciente: "Então ficou certo, o paciente manifestou o desejo de falecer em casa, a família por um momento concorda e quando chega o momento eles não suportam $e$ trazem o paciente que, às vezes, falece na ambulância, no trajeto, ou no pronto-socorro de uma forma bem ruim. Longe dos familiares, longe do seu ambiente" (E10).

Por todas essas questões a escolha do local do cuidado e da morte é apontada como algo desafiador do ponto de vista ético ${ }^{12}$. Por vezes, o paciente prefere determinado local para ser cuidado e morrer, porém isso pode não ser factível ou ético. Os autores sugerem que o planejamento para alta hospitalar do paciente com doença ameaçadora da vida considere se ele tem condições mentais para tomar essa decisão. Devem ser analisados, ainda, os riscos que o cuidado domiciliar pode significar para os cuidadores, suas opiniões, as fontes de recursos necessários e a qualidade do relacionamento entre paciente e familiares ${ }^{12}$.

A escolha do paciente deve ser facilitada sempre que possível, respeitando assim sua autonomia, mas deve-se evitar causar dano quando o cuidado domiciliar não for plausível, utilizando como critério o melhor interesse do paciente e o bem-estar dos envolvidos no cuidado. É papel da equipe de saúde, inclusive, explicar ao paciente por que suas preferências não podem ser facilitadas ${ }^{12}$.

\section{Considerações finais}

Os resultados da pesquisa permitiram identificar importantes questões pertinentes à autonomia do paciente em cuidados paliativos, sob o paradigma bioético da casuística. O dever de respeitar a autonomia do paciente foi reconhecido, porém foram identificados conflitos entre esse princípio e o de beneficência, principalmente quando o paciente recusa intervenção. A experiência em cuidados paliativos foi apontada como estímulo a uma atuação com maior respeito às preferências do paciente. Entrou em discussão, também, a moralidade de o paciente/ família participar de decisões sobre conduta médica.

O dever de veracidade foi reconhecido e a comunicação apontada como componente necessário para a relação terapêutica, sendo condição elementar para o paciente exercer autonomia. Paralelamente, o respeito aos limites emocionais do paciente com relação à ciência de más notícias foi colocado como necessário. Para fazer frente a essas demandas, ressalta-se a importância de os profissionais desenvolverem habilidades de comunicação.

O cerco do silêncio foi colocado como importante obstáculo para a autonomia e resolução de pendências por parte do paciente que ainda teria condições de decidir e atuar socialmente. Além disso, os profissionais de saúde podem enfrentar como um dilema ético a escolha da postura a adotar perante este cerco.

A escolha do local de tratamento e morte foi citada como importante aspecto dentre as preferências do paciente, embora seja reconhecida a dificuldade de viabilizar uma assistência adequada quando a escolha é pela própria residência. Nesse caso, fazse necessária a avaliação das necessidades e preferências do paciente juntamente com a disponibilidade de assistência formal e informal no domicílio.

O estudo evidenciou o destaque do tema da comunicação. O fato de a comunicação em cuidados paliativos muitas vezes incluir questões de forte conteúdo emocional a torna desafiadora para todos os envolvidos, o que frequentemente resulta na omissão de determinadas informações e atitudes paternalistas perante o paciente. Em paralelo, é reconhecido o seu papel enquanto instrumento para enfrentar problemas éticos, e ainda como prerrogativa para o exercício da autonomia, para a relação terapêutica, ajustamento psicológico e resolução de pendências. 


\section{Referências}

1. Jonsen AR, Siegler M, Winslade WJ. Clinical ethics: a practical approach to ethical decisions in clinical medicine. $7^{a}$ ed. New York: Mc-Grraw-Hill; 2010.

2. Tapiero AA. Las diferentes formas de morir: reflexiones éticas. An Med Interna. 2004;21(7):355-8.

3. Bélanger E, Rodríguez C, Groleau D. Shared decision-making in palliative care: a systematic mixed studies review using narrative synthesis. Palliat Med. 2011;25(3):242-61.

4. Beauchamp TL, Childress JF. Princípios de ética biomédica. São Paulo: Loyola; 2002.

5. Macauley R. Patients who make "wrong" choices [editorial]. J Palliat Med. 2011;14(1):13-6.

6. Kovács MJ. A caminho da morte com dignidade no século XXI. Rev.bioét. (Impr.). 2014;22(1):94104.

7. Pessini L. Distanásia: até quando prolongar a vida? São Paulo: Loyola; 2001.

8. Fallowfield LJ, Jenkins VA, Beveridge HA. Truth may hurt but deceit hurts more: communication in palliative care. Palliat Med. 2002;16(4):297-303.

9. Oliveira FT, Flávio DA, Marengo MO, Silva RHA. Bioética e humanização na fase final da vida: visão de médicos. Rev. bioét. (Impr.). 2011;19(1):247-58.

10. Slort W, Schweitzer BPM, Blankenstein HA, Abarshi EA, Riphagen I, Echteld MA et al. Perceived barriers and facilitators for general practitioner-patient communication in palliative care: a systematic review. Palliat Med. 2011;25(6);613-9.

11. Barbero Gutiérrez J. El derecho del paciente a la información: el arte de comunicar. An Sist Sanit Navar. 2006;29(3):19-27.

12. Wheatley VJ, Baker JI. "Please, I want to go home": ethical issues raised when considering choice of place of care in palliative care. Postgrad Med J. 2007;83(984):643-8.

\section{Participação dos autores}

Este manuscrito é parte dos resultados da tese de Carolina Becker, orientada pelo prof. dr. Paulo Antonio de Carvalho Fortes. Ambos colaboraram na condução da pesquisa e na elaboração do artigo, compartilhando, dessa forma, sua autoria.

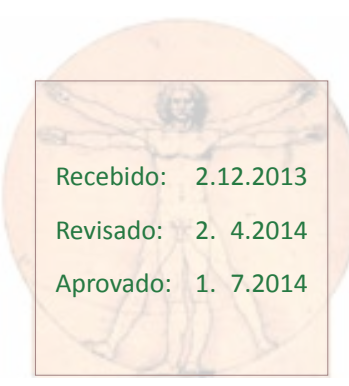

